\title{
Priests and healers of the Iranian speaking population of the upper ob region in the early Iron Age
}

\begin{abstract}
According to some Russian researchers, ${ }^{1,2}$ a considerable part of the population of the Upper $\mathrm{Ob}$ region in the Early Iron Age descends from the Iranian speaking people ${ }^{1,2}$ (Figure 1(1). In the second half of 1,000 BC, this region was characterized by close cultural ties with the "Saxon" world of the Central Asia and the Middle East. For instance, this factor manifests itself in the discovered graves of womanlike priests (Bystrovka-1) as well as certain medical tools and intravital trepanations (Bystrovka-2) of the parietal lobe of human scalps. Such peculiarities of archeological anthropologic materials from the Upper Ob region have obvious parallels with the Scythian mythology (Herodotus) concerning origination of Enarees (fortunetellers) known from the ancient descriptions (Pseudo-Hippocrates). The sophisticated character of medical tools that are similar with certain ancient samples and a high degree of neurosurgical professionalism of intravital trepanations performed in the ancient times testify to a profound healing experience frequently accompanying various rituals in the traditional culture. The Scythes have a lot of shamans who tell fortune with the help of multiple dowsing rods in the following way: after bringing large bunches of rods and putting them on the ground, they lay them out and then tell your fortune by moving rods one after another; when telling your fortune, they gather rods again and lay them out separately, one by one. It is their original way of telling fortune (Herodotus). The Scythes have a special professional priest corporation of Enarees - womanlike fortunetellers related to the cult of Artimpasa. They wear dresses, adopt feminine habits and even speak like women. The term Enaree originates from the Iranian word a-narya ("not masculine"). The Enarees were fortunetellers: according to Herodotus, "the art of telling fortune was given to them by Aphrodite; they tell fortune with the help of lime bark: a fortune teller cuts it into three stripes, then while intertwining them between his fingers and untwining them back, he delivers a prediction". The corporation of Enarees was of hereditary nature and included noble people. The Enarees were quite influential in the Scythian society. There are people among the Scythes who were born from the back of the head, they do all woman's work, they are called Enarees, or womanlike. Their congeners believe that their pathological condition was determined by gods; so they honor those who suffer from this disorder so as to avoid it themselves. As for me, I think that this disease is just the will of gods, that everything has its cause, which determines the subsequent course of events.
\end{abstract}

Keywords: the Iranian-speaking people, upper ob region in the early iron age, the enarees, herodotus
Volume 3 Issue 5 - 2018

\author{
AP Borodovskiy \\ Institute of Archaeology and Ethnography, Siberian Branch \\ Russian Academy of Science, Novosibirsk State University, \\ Russia
}

Correspondence: AP Borodovskiy, Institute of Archaeology and Ethnography, Siberian Branch Russian Academy of Science, Novosibirsk State University, Russia, Email altaicenter20II@gmail.com

Received: July 27, 2018 | Published: September 05, 2018

\section{Introduction}

The mode of ritual actions and healing is quite thoroughly represented in Kurgan 1 of Bystrovka-1. In one mass grave of this burial complex, three middle-aged and elderly men were buried. One of the buried was 35-40 years while the others were 50-60. ${ }^{3}$ The associated inventory (a metal mirror, two ceramic spinning wheels and two ritual stone altars) of all the buried had explicitly female characteristics. This grave can be interpreted as reflecting the practice known from the Scythian story by Herodotus on the Enarei who were womanish fortune-tellers. Such interpretation of the abovementioned grave of the Bystrovka-1 necropolis is also confirmed by the practice of healing sick men, which is known from the Middle Eastern texts. ${ }^{4}$ According to these rituals, sick men were given a mirror and a spinning wheel before their recovery. Then these items were taken back under any symbolic or ritual gates, which was accompanied by the following magic words: "look ... you have lost your femininity
... you have dropped your female habits». Such parallels in the set of associated items in the mass male grave from Bystrovka-1 (Kurgan 1) and the abovementioned ritual practice do not rule out the fact that they could be sorcerers and used magic rituals related to "sex realignment" for any healing or sacral purposes. The similar set of items (a mirror and a spinning wheel) discovered in the associated inventory of Kurgan 1 of Bystrovka-1 can provide for the fact that the buried men (or one of them) could perform quack functions and officiated at rituals related to "sex realignment" for any healing or sacral purposes. This form of magic actions could correspond to a certain religious practice and its specific agents. However, one has still to find out what "status" they had in the Early Iron Age. There is another controversial circumstance concerning the fact that as a rule in every large necropolis of the Novosibirsk Ob region there is at least one grave with a bronze mirror. Such discoveries are known not only in the Bystrovka-1 necropolis but also in the Verkh-Suzun-5 one. These burial grounds could be burial and commemorative centers 
of certain territorial groups of population while such single graves with mirrors reflected the presence of their own "sorcerers" in each of such unions. Their influence could spread over a certain region. According to the ethnographic materials concerning Siberia, shamans usually "controlled" a particular territory, especially in those ancient times when they "felt cramped" due to other shamans living nearby.

\section{Research}

For the Bystrovka necropolis (Bystrovka-1, 2, 3) on the whole, various healing practices are quite wide-spread at different levels (Figure 1(2-4)). One of them is represented by an object complex. Besides items associated with the ritual practice (mirrors, spinning wheels and altars), it includes an array of products fully corresponding to the specialized ancient medical tools. There are first of all several bronze items discovered in a number of graves in Bystrovka-1 which were erroneously interpreted by TN. Troitskaya as hairpins. In fact, such items are fully similar to ancient scoop catheters used for administration of drug doses that are well-known based on the ancient
Roman medical tools of the Mediterranean and Black Sea regions. It is also noteworthy that the presence of stone altars in the graves of "womanish" men in Kurgan 1 of Bystrovka-1 was likely to be related to a certain ritual and magic activity, e.g. to numerous acts of painting bodies of the buried men in the kurgan group of Bystrovka-2. Besides, the similar red colorant of mineral origin was discovered not only on different parts of bony tissues of the buried men (their heads, lumps and bodies) but also inside several stone altars that were used for paint rubbing. One should emphasize that the mere altars were part of ritual actions. First, not only whole products but also fragments thereof were put into graves. Second, these fragments generation was already implied in the course of the finished product manufacturing and decoration from the constructive point of view. On the reverse side of these altars, between four legs thereof, there was always a deep X-shaped cut in the stone material of the product, along which the item subsequently broken down into separate parts. Such facts of placing parts of stone altars into the graves were identified in the Upper Ob region not only in Bystrovka-2 but also in Novotroitskoe-2.
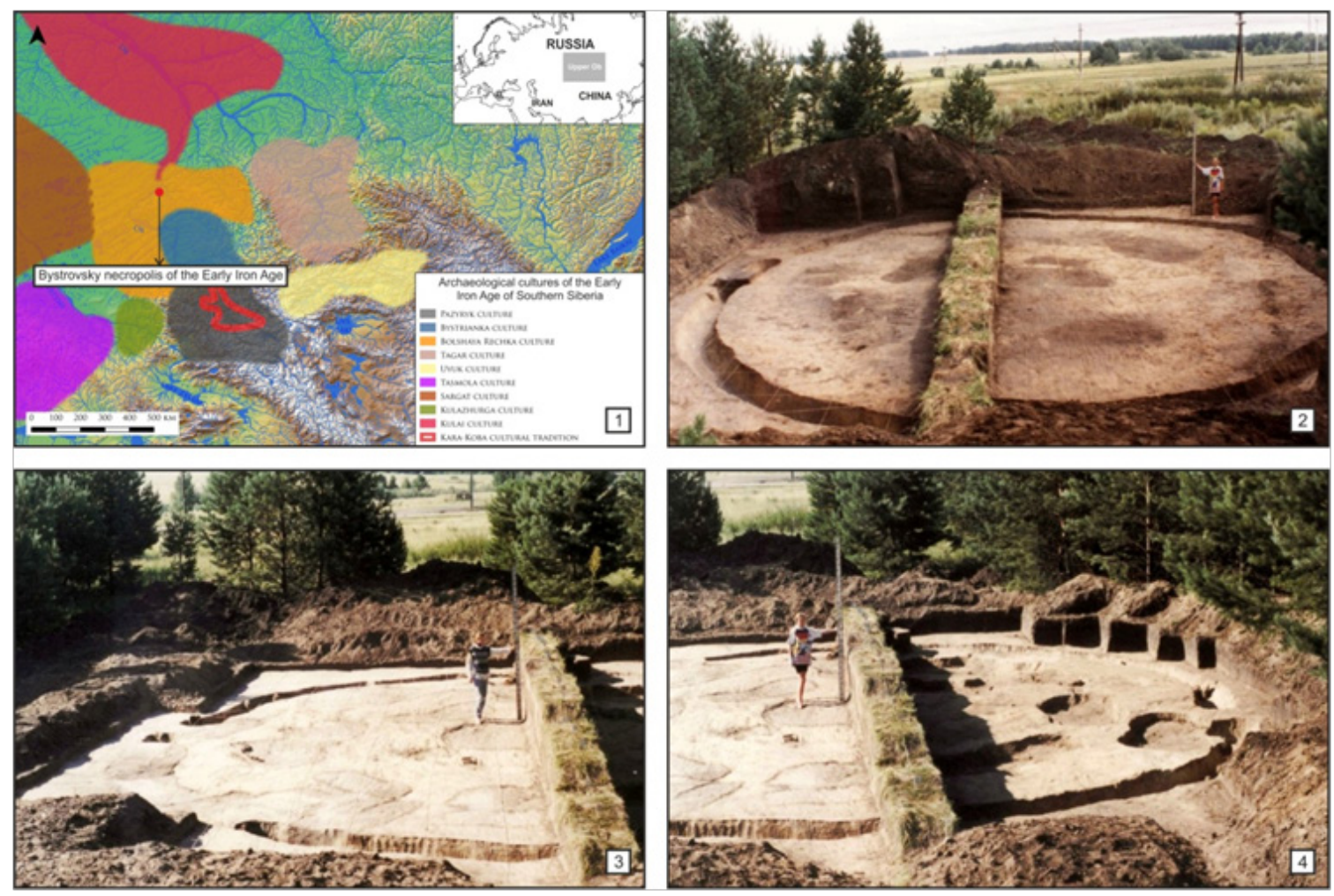

Figure I Bystrovsky necropolis of the early iron age of the Upper Ob area. (I) Map of archaeological cultures from the Early Iron Age of the Upper Ob region. (2-4) Multi-burial mounds of the Early Iron Age of the burial group Bystrovka-2 (2 - mound-6, 3-4 - mound-5).

Another level of medical possibilities of the healers of the Early Iron Age in the Upper Ob region is well and quite vividly illustrated by the mass anthropologic material. It deals with consequences of craniotomy which could be different not only by typology of its execution but also by a potential character of medical effect in the sphere of neurosurgery and lethality of these medical operations. One should emphasize differences and peculiarities within the framework of the technique of resection (decompressive) craniotomy. This medical operation was performed by several technical methods. One of them was cutting a bony tissue of the skull vault to make a trephine opening. The form of an opened skull cavity could be either round or polygonal, which is closer to a pentagram. The same skull opening form was ensured by means of prior drilling and subsequent cutting of the entire cavity to be opened. In most cases, skulls of those people buried in Bustrovka-2, 3 were trepanized by destroying bases thereof after people's death. Similar rituals are identified in the Early Iron Age in respect of skulls discovered in the Minusinskaya Hollow, Western Mongolia and Kazakhstan (Figure 5-9). ${ }^{5}$

The authentic traces of this operation are identified on several skulls from Bystrovka-2 (Kurgan 9) and Bystrovka-3 (Kurgan 6). Two burial grounds demonstrate single-type deterioration of the base and symmetric destruction of lateral areas of occipital bones. Nevertheless, one should emphasize a certain difference between these trepanized skulls. First of all, the skull openings differ by their 
nature. While on the skull from Bystrovka-3 a bone part is removed by means of prior drilling and sewing, on all skulls from Bystrovka-2 this operation was performed by a cutting tool without prior marking. Therefore, the trephine opening from Bystrovka-3 has a more regular geometrical shape that is close to the subsquare. The similar openings on the skulls from Bystrovka-2 are obviously larger and have irregular ragged edges. The general contour of the opened parts corresponds to ovals (Figure 2(10-12)). The form of trephine openings (a polygon) and a technology of their execution, i.e. drilling (Bystrovka-3) and chopping and cutting (Bystrovka-2), allows raising an issue of special traditions and options of craniotomy in the Novosibirsk Ob region in the Early Iron Age as well of an individual manner of the operator. One should emphasize that cases of trepanation of skulls from the Bystrovka necropolis can be interpreted in a number of ways. First of all, it is noteworthy that the form and "functional" destination of trephine openings in the bases of skulls from Bystrovka-2, 3 are rather close to the so-called encephalophagy, i.e. eating of the dead person's brain by his/her relatives. According to the Monte Circeo materials, this ritual was practiced even by the Neanderthals and was preserved up to the ethnographic time by certain isolated groups of population of Oceania (the Papuans of New Guinea). Such actions as a desire to "remove or release" a dead person's soul are likely to be just one of the numerous explanations of the skull vault destruction. It is obvious that, besides a sacral and ritual meaning, the procedure of craniotomy could have a certain medical meaning for the people that left the Bystrovka necropolis.

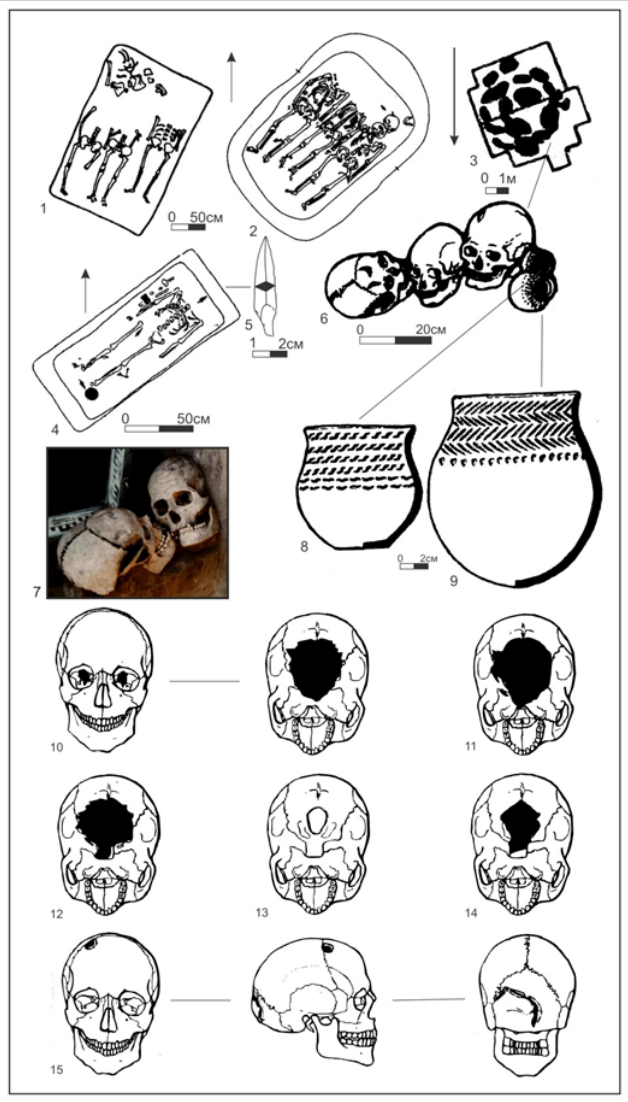

Figure 2 Cut off heads from the burial complexes of the Early Iron Age of the southern part of Western Siberia. $(1,2,4)$ Collective headless depositions from Bystrovka, (2-5) A deposition without the head, which is replaced by a boney arrowhead, Bystrovka-I (Burial Mound 4, Grave 3). (3,6,7, I0-14) Cut off and trepanized skulls (Bystrovka-2, Burial Mound 10). (8) A ceramic vessel of the Kulai archeological culture. (9) A ceramic vessel of the Sargat archeological culture. (I5) A trepanized skull (Bystrovka-2, Burial Mound I0).
Resection trepanation of human skulls was also very important. According to the Bystrovka necropolis materials, one can define three main parts of the skull that were commonly trepanized in the Early Iron Age, including a parietal vault, a back of the head and a skull base. Besides, the trepanation area was essentially related to a factor of fatal outcome for the patient or a ritual practice. For example, resection trepanation performed on the parietal vault usually lacked any features of the bony tissue regeneration. It obviously testifies either to a fatal outcome of the performed trepanation surgery for the patient or any postmortem actions in respect of the dead person's head. The similar situation is also typical of resection trepanation (with cutting or drilling) performed on the skull vault base. Actually, trepanation of this part could be conducted with the head that was already cut and was integrated into a certain ritual. It is interesting that in one case (Bystrovka-2, Kurgan 9) such actions were performed with the heads of the people belonging to different tribes. It is unambiguously confirmed by the associated ceramic vessels referred to foreign cultures, i.e. the Western (Sargat) culture and the Northern (Kulai) culture (Figure 2(8,9)). Thus, it is quite logical that one of the women's skulls buried in Kurgan 9 had clearly expressed anthropologic taiga features bringing it closer to the northern population of the $\mathrm{Ob}$ region (the Kulai culture). Besides, one of the ritually buried skulls was characterized not only by trepanation of the vault of the cut head but also by destroyed bones of the orbit floors, which testifies to blinding (Figure 2(10-15)). According to the beliefs of the Siberian peoples, the head was a home of the soul. Thus, the Selkups regarded the head as a temporary repository of the grave soul that could not leave the dead person's body until it decays. ${ }^{6}$ The Nganasans associated the soul with the brain and eyes. According to the ethnographic materials, sometimes they performed actions that should have helped remove the soul. There is certain evidence that this ritual was common in Tuva by burial of very old people. Their head was broken through. All these ethnographic parallels can be regarded not only as an illustrative comparison for the procedure of burial of skulls in the Bystrovka necropolis (Kurgan 9, Bystrovka-2) but also have a more profound meaning. The matter is that the skull bones broken through in the orbit floors and trepanation were obviously aimed at removing eyes and brain of the dead people (Bystrovka-3) and immolated people (Bystrovka-2).

Certain graves with human heads have been long known in the sanctuaries of Western Siberia referred to the Early Iron Age on the territory of ancient settlements of the Middle Irtysh region Bolshoi Log [Алябина, Коников, 1995] and the Middle Ob region - Sarovskoe ancient settlement. ${ }^{7}$ These graves usually contained ceramic vessels. The presence of ceramic vessels in the vicinity of skulls is most frequently interpreted as protective rituals performed in the "border-line" situation when the world of the living and the world of the dead lose their boundaries. This viewpoint is certainly true, especially taking into account the facts of putting ceramic vessels into the ditches of kurgans (Kurgan 6, Bystrovka-2) being one of the actual boundaries of the family cemetery. Along with such facts of a ritual attitude to heads, one should mention numerous cases when skulls were missing in a number of one-person (Bystrovka-1) and mass (Bystrovka-3) graves of the Bystrovka necropolis (Figure $2(1,2,4))$. It is also important that trepanation of the cut head base was also identified in the graves of the kurgan group of Bystrovka-3. Besides, practically the same multi-grave kurgans (Kurgan 10, Bystrovka-2) account for the cases of a sufficiently long life of the patient after resection trepanation performance, which is evidenced by considerable bone tissue regeneration. It is proved by a skull from Woman Grave 5 (Layer 1), Kurgan 10, Bystrovka-2 (Figure 2(15)) possessing signs of furunculosis on the parietal vault and traces of 
intra-vitam parietal trepanation. Regeneration of bone tissue edges (on the polygonal trepanation plate that is typical of the Bystrovka necropolis) testifies to the fact that the woman lived quite long after this complex surgery. The social status of the buried woman was not very high if compared with the elite grave belonging to the Pazyryk culture from Berel where a male skull also had traces of the similar head surgery. Circular undercutting of the edges of the parietal vault that was probably destroyed as a result of falling off a horse was aimed at removing fragments of skull bones to prevent brain edema. But unlike the abovementioned operation performed according to the Bystrovka materials, that surgery had a fatal outcome for the patient.

The signs of trepanation on different parts of skulls of the dead from the Bystrovka necropolis allow approximately assessing a degree of their neurosurgical effect. Besides ritual actions with such cut skulls, the intra-vitam trepanation of the female skull discovered in Kurgan 10 of Bystrovka -2 can testify to certain neurosurgical operations performed for medical purposes. The therapeutic effect of such trepanation variety could be related to removal of the developing brain edema after an acute head injury. The traces thereof are quite vividly presented on the parietal vault of this female skull. On the whole, this part of the skull corresponds to the most critical brain areas. Any damage of this area can lead to visual disturbance, deterioration of eye memory, movement coordination, balance, inborn reflexes (gagging, swallowing) and autonomic nervous functions (breathing, blood pressure, metabolism, cardiac function). One should also emphasize that according to the results of the complex modern research, the level of resection trepanation in the south of Western Siberia in the Early Iron Age was very high, which was impossible without quite precise ideas of the brain anatomic features required for successful neurosurgical operations. It is necessary to somehow elaborate on interpretation of the purpose of operations related to resection trepanation of a number of skulls from the ritual grave in Kurgan 10, Bystrovka-2. First, the opinion that trepanation was performed solely in order to make openings in the skulls to put them on the poles is erroneous. This hypothesis does not take into account incomparability of the technical complexity of resection trepanation solely to make openings to put a skull on the pole. This objective could be achieved in a much easier way. Particularly, using a natural opening of human skull in the connecting point of the skull and spinal column, it results in cutting a cervical region of the vertebral column. It is also noteworthy that a complex technique of resection trepanation (drilling, cutting) applied on these skulls fully corresponds to the technology of this operation on skulls from ordinary graves of the Bystrovka necropolis (Bystrovka-2, 3). Finally, the opening in the base of these skulls generated in the course of their primary trepanation could be also used for putting on the poles. Judging by the graphic sources of the Scythian toreutics, this practice was really known in the Early Iron Age, namely, it was an image of warriors holding cut human heads by the hair on a golden cap discovered in the Kurdjipsky kurgan belonging to $400 \mathrm{BC}$ (the Kuban region). ${ }^{8,9}$

\section{Conclusion}

To sum it up, one should point out that in the Early Iron Age certain representatives of the Iranian speaking population of the Upper $\mathrm{Ob}$ region not only possessed medical tools of an ancient type but also practiced quite well-developed neurosurgical technologies used for ritual and medical purposes. Numerous facts of successful performance of complex neurosurgical operations among ordinary representatives of the population imply quite a high level of social availability of these medical operations in the Early Iron Age under the conditions of conventional society. Nevertheless, in ancient times healing and ritual practices were considered a unified whole.

\section{Acknowledgements}

None.

\section{Conflict of interest}

Author declares that there is no conflict of interest.

\section{References}

1. Alyabin VP, Konikov BA. Ancient sanctuary on the outskirts of Omsk. Monuments of history and culture of the Omsk region. Omsk; 1995.

2. Galanina LK. Kurdjipsky mound L. 1980; 93 p.

3. Gurney OR. Hetty M. 1987; 144 p.

4. Mednikova MB. On the issue of the spread of post-mortem trephination of skulls in Central Asia. RA. 1997;4:130-139.

5. Mogilnikov VA. The population of the Upper Ob region in the middle of the second half of the 1st millennium BC. 1994; $195 \mathrm{p}$.

6. Pelikh GI. Origin of Selkup. Tomsk; 1972. p. 115-116.

7. Troitskaya TN. Bystrovka-1 burial ground as a historical source. Archaeological monuments of the forest-steppe belt of Western Siberia. Novosibirsk; 1983. p. 59-63.

8. Troitskaya TN, Borodovsky AP. Bolsherechenskaya culture of the forest-steppe Ob region. Novosibirsk; 1994. 219 p.

9. Chindina LA. Sarov fortification. Questions of archeology and ethnography of Siberia. Tomsk; 1978. 